\title{
TÊXTIL LAR: gestão de design das marcas nacionais do Grupo Coteminas
}

Mariana Costa Laktim;

Rita de Castro Engler;

Júlia Baruque-Ramos

\section{resumo:}

O presente estudo faz uma análise das quatro marcas mais importantes do Grupo Coteminas (Springs Global), a escolha por essa empresa justifica-se por ser uma das maiores indústrias do Brasil e possuir a cadeia têxtil totalmente verticalizada. As marcas escolhidas foram Casa Moysés, Mmartan, Artex e Santista, por serem de consumo interno brasileiro. O ponto de partida para a pesquisa foi a entrevista com CEO Mário Sette, que classifica o público alvo de cada marca. Por seguinte, uma visita campo foi feita nas lojas para análise do layout, obtenção de catálogos físicos e digitais e análise dos produtos de cada marca. Com o conjunto dos dados e imagens obtidos, foi possível explorar o processo de gestão de design de cada marca e a implantação do design thinking nos produtos (têxtil para o lar e decoração).

palavras Chave: design; gestão; home textile; Grupo Coteminas 


\section{Introdução}

O enxoval de cama, mesa e banho é conhecido desde a antiguidade. Era confeccionado à mão e a quantidade de peças era diretamente relacionada a situação financeira da família. O enxoval de uma noiva era composto por: itens de lençóis de linho e/ou algodão, toalhas de mesa e banho, guardanapos de pano, todos os itens em tecido branco e com monogramas bordados. Com o passar dos anos, passou e continua passando por modificações que se devem a evolução tecnológica, acesso a diferentes tipos de matéria prima, mudança no comercio e mercado, diferentes classes sociais e consumidores.

No Brasil, observa-se também uma evolução em suas características ao longo do tempo, através de matérias têxteis, processos de fabricação e moda (design), com sua importância econômica crescente. Uma empresa do ramo têxtil que representa esse crescimento do setor cama mesa e banho é a Coteminas. Foi fundada em 1967 em Montes Claros por José Alencar e hoje está presente em vários países.

A presente pesquisa apresenta uma análise das quatro marcas mais importantes do Grupo Coteminas (Springs Global): Casa Moysés, Mmartan, Artex e Santista, por serem de consumo interno brasileiro. A revisão bibliográfica desenvolvida foi baseada em conceitos fundamentais de Gestão do Design e Design Thinking presentes na empresa em relação aos seus produtos e funcionamento.

A metodologia descreve como foi feita a análise dos produtos, catálogos e Layout das lojas e pontos de venda. Ao final são apresentadas as principais conclusões com base no que foi apresentado e analisado nesta pesquisa.

\section{Metodologia}

Quanto a finalidade, a presente pesquisa é aplicada e com relação a abordagem é qualitativa. Quanto aos objetivos é exploratória descritiva. Os procedimentos utilizados para coleta de informações foram pesquisa bibliográfica e documental, pesquisa de campo com visitas técnicas e entrevistas semiestruturadas.

Os dados para elaboração desse estudo foram coletados através de análise bibliográfica em literaturas científica e técnica pertinentes ao assunto abordado, assim como visitas técnicas e entrevistas semiestruturadas a empresa ligada ao setor de têxtil para o lar no Brasil.

De acordo com Vergara (2000), a finalidade do trabalho tem um caráter de pesquisa aplicada, pois ela é fundamentalmente motivada pela necessidade de resolver problemas concretos, mais imediatos ou não. Essas abordagens utilizam-se, com maior frequência, de 
análises qualitativas, tendo as descrições como uma significativa contribuição para a pesquisa.

A pesquisas qualitativas permitem que o pesquisador se aprofunde no estudo do fenômeno ao mesmo tempo em que tem o ambiente natural como fonte direta para a coleta de dados. Além disso, este estudo contempla uma pesquisa descritiva, apresentando características de determinado fenômeno, firmando correlações entre variáveis e definindo sua natureza (VERGARA, 2000).

Gil (2008) afirmou que algumas pesquisas descritivas vão além da simples identificação da existência de relações entre variáveis, pretendendo determinar a natureza dessa relação. Já, a abordagem do trabalho é de pesquisa de campo, uma vez que o pesquisador vai até o ambiente natural do seu objeto de estudo (GIL, 2008).

Por sua vez, Vergara (2000) destaca que nesse caso o investigador deixa de ter total controle sobre as variáveis, se limitando a identificar e coletar informações sobre o seu objeto de estudo no contexto original de vivência.

\section{Revisão da literatura}

\subsection{Têxtil para o lar}

O enxoval na antiguidade, tradicional para uma noiva, era constituído por artigos têxteis para cama, mesa, banho e utensílios do lar. A confecção do enxoval tinha início nas rodas de fiar ou nas rocas feitas pelas próprias mulheres. Após o fio pronto elas realizavam os tecidos em teares manuais, e a partir daí começavam a bordar. (Harris, 2006)

A estimação dada ao enxoval é associada às tradições e à cultura, dentro de uma distinção econômica e religiosa das mulheres. Os valores ligados ao enxoval vão desde a apreciação de requintes da casa à educação da mulher. A prática do enxoval era um processo artesanal e realizado pelas futuras noivas, familiares e empregadas. Realizava-se um contrato entre os pais dos noivos ou diretamente com o noivo. O Enxoval fazia parte do dote no casamento e era de suma importância (PINTO et al., 2009). Ao longo dos dois últimos séculos, diminuiu a dedicação para poder realizar o seu próprio enxoval, criando a necessidade da simplificação dos acabamentos e/ou de adquirir os produtos acabados no comércio. Conforme a demanda, houve o aumento da facilidade de encontrarem-se os produtos em lojas de departamento próprias de Moda Casa (ou Moda Lar), as quais proporcionam todos os produtos necessários para a montagem do enxoval.

No momento da escolha dos produtos têxteis para o lar, os quatros principais fatores que os consumidores avaliam ao adquirir lençóis são: tamanho, suavidade, durabilidade e preço, permanecendo os mais importantes e sem mudança ao longo dos 
anos. Os fatores que ganham a maior popularidade são o valor agregado do produto e o tecido $100 \%$ algodão. Em adição, os consumidores estão cada vez mais conscientes da importância da contagem de fios nos tecidos com relação à qualidade do produto final (DAS, 2010).

As roupas de cozinha estão presentes na forma de aventais, guardanapos, luvas, toalhas, panos de prato, etc. É muito importante garantir a segurança ao lado da sua funcionalidade deste setor do têxtil empregado na cozinha. De acordo com Das (2010) é aconselhável usar têxteis na cozinha feitos de tecido de linho ou de algodão. Suas características permitem serem laváveis e duráveis, além de menos propensos ao fogo. $\mathrm{O}$ algodão é o mais popular e tem uma demanda muito constante, porém, muitos compradores ainda preferem tecidos de poliéster; misturas de algodão e poli tecido.

Tecidos felpudos tornaram-se muito importantes no setor de têxteis para o lar. Tradicionalmente, o algodão é uma escolha natural para a produção de toalhas de felpa. Com significado de mudança no estilo de vida e demanda de vários aspectos funcionais, os fabricantes de toalhas estão à procura de produtos únicos, inovadores e diferentes. Toalhas feitas de viscose de bambu e algodão são $25 \%$ mais suaves do que toalhas feitas inteiramente de algodão após lavagem. Ao adicionar fibras de soja ao algodão, as toalhas apresentaram melhora de sensação de toque e absorção (DAS, 2010). Na Tabela 1 apontam-se os produtos de cama, mesa e banho conforme encontrados em diversos sites de produtos no Brasil.

Tabela 1 - Linhas e descrições dos produtos de cama, mesa e banho, conforme encontrado em sites de produtos no Brasil

\begin{tabular}{ll} 
Linhas de produtos & Descrição dos Produtos \\
\hline & Travesseiro \\
& Fronha (superfronhas) \\
& Capa protetora de travesseiro \\
& Capa protetora de colchão \\
& Lençol (malha/ plano/ com elástico / bordado - \\
& solteiro/viúvo/casal/quen/ king/ super king) - Virol para edredom \\
& Coberta felpuda/ mata/ cobreleito / edredom / capa para \\
& (duvet) \\
Cama & Saia de cama \\
& Manta decorativa (peseira) \\
& Colchas \\
& Protetor de travesseiro \\
& Almofadas \\
& Toalha Banho (Feminina/Masculina) \\
& Toalha Banhão
\end{tabular}




\begin{tabular}{ll} 
Toalha Rosto & Toalha de Lavabo (mão/higiene) \\
Toalha de Praia \\
Toalha de Piscina \\
Toalha toca de banho \\
Toalha Roupão \\
Toalha de Piso (tapetinho) \\
\hline Toalha de mesa \\
Jogo americano \\
Guardanapo \\
Pano de Copa (prato/ copo) \\
Pano de limpeza (TNT) \\
Passadeira (tapete) \\
Trilho de mesa \\
Avental \\
Cortinas \\
\hline
\end{tabular}

Fonte: Mariana Costa Laktim (2018)

\subsection{Mercado do têxtil lar no Brasil}

Os maiores mercados em crescimento em todas as categorias de produtos têxteis lar estão no Brasil, Rússia, Índia e China. O Relatório Mundial do Mercado Têxtil da Organização Mundial do Comércio (OMC) de 2005 mostrou que os EUA eram o maior importador de produtos têxteis lar (34,3\%), seguindo-se Alemanha (11,6\%), Japão (10,9\%), Reino Unido $(8,3 \%)$, França $(6,5 \%)$ e Canadá $(4,2 \%)$. Por outro lado, o maior exportador de produtos têxteis lar foi a China, com 33,4\% do mercado mundial, seguida do Paquistão (12,1\%), Índia (9,7\%), Turquia (6,6\%), Portugal $(4,8 \%)$ e México $(4,5 \%)$. Acredita-se que a China permanecerá líder mundial em exportações, enquanto é incerto que os EUA serão o maior importador de produtos têxteis lar (DAS, 2010). Em 2004, o valor relativo ao mercado de toalhas dos EUA foi de US\$ 715.575.000 (YILMAZ et al., 2005).

O Brasil é um dos maiores consumidores mundiais de produtos têxteis, mas, em termos de exportação internacional sua contribuição é pequena atingindo a $26^{\circ}$ posição. Entretanto, a linha lar foi que teve maior crescimento de 2010 a 2014, com elevado índice de 14\% (Instituto de Estudos e Marketing Industrial, 2015). Portanto, os modelos de inovação corroboram o indicador da sistematização do procedimento da evolução do design e da indústria moda lar, sendo o aumento de participação na economia do mercado sua principal meta.

No mercado têxtil norte-americana, a categoria banho provou ser um segmento crescente em têxteis para o lar em 2004, ganhando 2,8\% nas vendas, para US \$3,7 bilhões, dos quais $51 \%$ é toalhas em US \$1,881 bilhões (CORRAL, 2005). 


\subsection{Design no têxtil lar no Brasil}

Para Das (2010) o cliente procura harmonia e equilíbrio, impacto visual na casa e em todos os ambientes. Deve-se olhar para conjuntos de lençóis, edredons, tapetes, almofadas, cortinas, papel de parede que combinam bem com a cor do ambiente, mobiliário, piso, etc. Os designers têm que compreender a sensibilidade estética e a necessidade dos clientesalvo e criando inovações e conceitos na moda e ideais para satisfaze-los. Toda a coordenação de textura, cores e estampas tem que estar em harmonia com as tendências e o ambiente da casa. Os fabricantes têm de atender à demanda do mercado para atingir suas vendas satisfazendo os clientes.

\subsection{Gestão do Design}

O Gerenciamento do Design envolve, de acordo com Best (2006), gerenciamento de projetos, que são pagos por clientes (organizações, empreendimentos, negócios) e são colocados em prática por um Designer, um time de Designers ou uma consultoria de Design. Design envolve o processo de fazer, assim como o resultado final desse processo.

Ao gerenciar um processo de design, o foco é demonstrar como a estratégia pode ser visível através do designer, como o design pode ser usado para construir, moldar a presença e experiência de uma Organização e assim influencia como essa organização e sua marca são representadas ou percebidas (BEST, 2006).

\subsection{Design Thinking}

As ações das empresas está prestes a reverter uma tendência de várias décadas de montagem e terceirização da criatividade. A ação do design se irradia da função para se tornar um modo de resolver problemas e coisas que é amplamente usado em uma série de situações e configurações de negócios. O design cria estratégias para o crescimento e a inovação, em suposições inteiramente diferentes sobre como as pessoas querem viver e o que precisam (NIXON, 2016).

\subsection{Benchmarking}

O processo do Benchmarking é uma metodologia sucessiva e metódica para avaliar produtos e processos de trabalho de organizações que são como representantes das aperfeiçoes práticas, com o objetivo de progresso organizacional (SPENDOLINI, 1992).

Os procedimentos de benchmarking se sintetizam em cinco etapas (SHETTY, 1993): IDeterminar do que fazer benchmarking; II- Identificar parceiros; III- Coletar e analisar dados; IV- Estabelecer metas; V- Implementar ações e monitorar progresso. 
O êxito de um projeto de benchmarking está relacionado ao conjunto de dados envolvendo a alta gerência, proporcionando a base e provendo os recursos necessários para sua implementação e seu desenvolvimento; de uma modificação cultural na associação, que valoriza o aprendizado de terceiros; e a disponibilidade de referências a respeito do objeto a ser estudado, fator este que pode ser complicado no momento que se realiza o benchmarking competitivo (ELMUTI\&KATHAWALA, 1997).

A análise dessa metodologia é referente ao desenvolvimento de produtos, custeio $\mathrm{ABC}$, atingir os clientes-alvos, distribuição, e-commerce entre outros. A finalidade destas marcas é identificar os melhores processos de negócio em estudo, os quais quando implementados obterem o desempenho elevado.

\section{Análise dos resultados}

\subsection{O Grupo Coteminas}

Conforme o site do Grupo Coteminas (2017), em 1967, foi fundada, em Montes Claros, a Companhia de Tecidos Norte de Minas, Coteminas, a inauguração da fábrica de fiação e tecidos, a mais moderna de todas quantas existiam, deu-se em 1975. José Alencar, era o proprietário do Grupo Coteminas e em 1996, o seu filho assumiu como executivo titular do Grupo Coteminas o Josué Christiano Gomes da Silva. Hoje o Grupo Coteminas é composto de quinze fábricas no Brasil, cinco nos EUA, uma na Argentina e uma no México, e mais de quinze mil colaboradores. Seus produtos são enxoval completo para casa, fabricação de tecidos, fios etc. A principal empresa têxtil no mercado brasileiro com ciclo completo da Cadeia Têxtil e muito rica em história e evolução econômica para o Brasil. Hoje seu escritório administrativo e de estilo se localiza na Avenida Paulista em São Paulo.

\subsection{As Marcas}

A entrevista realizada foi com CEO Mário Sette (Grupo Coteminas AS - Springs Globo AS), nela foi perguntado sobre o contexto histórico, as marcas que o grupo tem, dentre outras. Nos anos 1979, a companhia monta uma tinturaria e plantas de beneficiamento para acabar tecidos. Em 1984, realizou a segunda instalação em Minas, a COTENOR. Em 1997, o Grupo Coteminas comprou as marcas Artex e Santista. Esta última com operação também na Argentina, sendo o primeiro passo de internacionalização da companhia. Em 2006, ocorreu o grande passo com a criação do grupo Springs Globo AS, hoje com fabricas na Argentina, Estados Unidos e operação no Canadá. Em 2008, foi comprada a operação de varejo da MMartan, a qual foi mais um avanço da companhia no sentido da verticalização. 


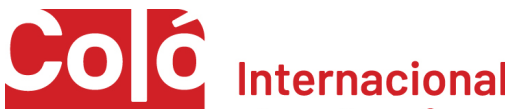 \\ guf de design \\ EDIÇÃO 2020}

Em 2011, houve início a abertura de algumas lojas da Artex, sendo que em 2017 essa empresa tinha 220 lojas de varejo no Brasil.

No Brasil a liderança das marcas são: Casa Moisés, para o público 'AA'; MMartan, público 'A'; Artex, 'AB'; e Santista, 'BC'. Na Argentina, as marcas locais são: Arco Íris (corresponde a marca Artex no Brasil) e a marca Fantasia (correspondente a Santista). O Grupo Coteminas atualmente atende mais de 30 mil clientes e está em todos magazines e lojas de departamentos no Brasil, como: Pernambucanas, Riachuelo, Avenida, Havan, Ferreira Costa, Jurandir Pires, Preçolandia, Niazi Chohfi, Carrefour, Wal-Mart, Grupo Pão de Açúcar, Cencosud, etc. e também em lojas pequenas, lojas especializadas, supermercados, grandes superfícies, com uns centos e poucos mil pontos de venda no Brasil.

\subsection{Design: produtos, catálogos e espaço de venda}

Os dados e imagens adquiridos, foram observados nos produtos de têxtil para o lar, nos catálogos dos produtos do grupo (adquirido nas lojas e na entrevista realizada) e nos espaços de vendas que foram visitados para análise de design da loja, vitrine e exposição dos produtos.

\subsubsection{Os produtos}

As análises dos produtos foram a partir da qualidade, do material, processo, acabamento e design.

_ Casa Moysés (Figura 1A), os produtos de alta qualidade com acabamento impecável sem nenhum defeito na peça, os materiais utilizados normalmente são fibras naturais nobres como; $100 \%$ algodão, algodão egípcio, seda, linho dentre outros. O processo da produção do tecido mais comum é o plano podendo chegar até 1000 fios por polegadas de urdume, também tem o matelassê, acetinado e jacquard como processo têxtil. Em relação do design são mais lisos e comum o processo de bordado nas peças proporcionando uma personalização dos produtos e nobrezas. Os preços dos produtos (em 2020) variam de doze mil e quinhentos reais (kit colcha e jogo de cama de seda) à quarenta reais (toalha lavabo).

_ MMartan (Figura 1B), os produtos de alta qualidade com ótimo acabamento nas peças, os materiais utilizados normalmente são fibras naturais nobres como; $100 \%$ algodão, algodão egípcio, seda dentre outros. O processo da produção do tecido mais comum é o plano podendo chegar até 400 fios por polegadas de urdume, também tem o matelassê, acetinado e jacquard como processo têxtil. Em relação do design são estampados, lisos e produtos bordado nas peças proporcionando nobrezas ao produto. Os preços dos produtos (2020) variam de um mil e oitocentos reais (kit colcha e jogo de cama) à trinta e cinco reais (toalha). 


\section{0 U. de design

_ Artex (Figura 1C), os produtos de ótima qualidade e acabamento, os materiais utilizados normalmente são fibras naturais, artificiais, sintéticas e mista como; $100 \%$ algodão, algodão egípcio, viscose, poliéster, acrílico dentre outros. O processo da produção do tecido mais comum é o plano podendo chegar até 400 fios por polegadas de urdume, também tem o matelassê, percal, acetinado e jacquard como processo têxtil. Em relação do design são estampados, lisos e produtos bordado nas peças proporcionando diferencial no produto. Os preços dos produtos (2020) variam de seiscentos e cinquenta reais (kit colcha e jogo de cama) à dez reais (toalha lavabo).

_ Santista (Figura 1D), os produtos de boa qualidade e acabamento, os materiais utilizados normalmente são fibras naturais, artificiais, sintéticas e mista como; 100\% algodão, poliéster, acrílico dentre outros. O processo da produção do tecido mais comum é o plano podendo chegar até 200 fios por polegadas de urdume, também tem o matelassê como processo têxtil. Em relação do design são comuns estampados e lisos. Os preços dos produtos (2020) variam de trezentos e seiscentos reais (kit colcha e jogo de cama) à cinco reais e cinquenta centavos (toalha lavabo).

Figura 1 - Produtos por marcas do Grupo Coteminas

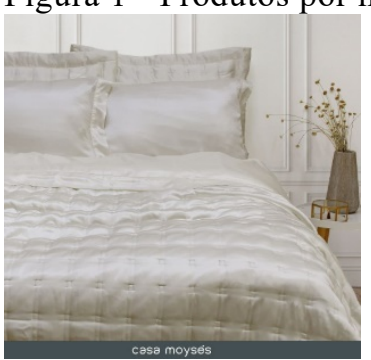

A

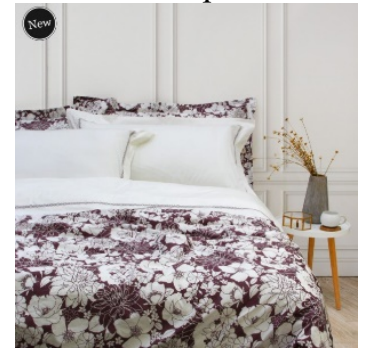

B



$\mathrm{C}$

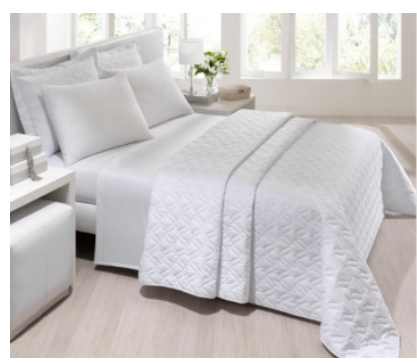

$\mathrm{D}$

Fonte: Grupo Coteminas (2020)

Legenda: (A) Casa Moysés, (B) MMartan, (C) Artex e (D) Santista.

\subsubsection{Os catálogos}

As análises dos catálogos foram a partir da qualidade da impressão, do papel e design. Os sites de e-commerce em relação aos produtos são padronizados, mudando somente o design com afinidade a marcas.

_ Casa Moysés (Figura 2A), com impressão digital de alto padrão, o papel impresso sofisticado, há também impressão de alto relevo, aplicação de tecido na lateral do catálogo fazendo o acabamento da lombar. Em relação ao conteúdo e as fotos são clean realçando os produtos, os locais são bem refinados, algumas das fotos são com uma modelo e outros sem.

- MMartan, existem duas formas de apresentações impressas dos seus produtos, uma em catálogo (Figura 2B) e outra em revista (Figura 2C). O catálogo com impressão digital de alto 


 guro de design

padrão, o papel impresso de ótima qualidade (couché com alta gramatura). Em relação ao conteúdo e as fotos são clean realçando os produtos, os locais são bem refinados, algumas das fotos são com uma modelo e outros sem. A revista a impressão de alta qualidade e o papel couché de menor gramatura, o conteúdo apresenta fotos dos produtos e reportagem sobre ambiente, celebridades e clientes que tem afinidade a marca e dicas de bem-estar.

- Artex (Figura 2D), com impressão digital de alto padrão, o papel impresso de ótima qualidade (couché com alta gramatura) e aplicação de resina localizada. Em relação ao conteúdo, as fotos são clean realçando os produtos, os locais são bonitos, não utiliza modelo nas fotografias.

- Santista (Figura 2E e 2F), os catálogos são específicos para os representes do Grupo Coteminas para serem apresentados e/ou entregue aos compradores dos magazines ou lojas deste departamento. A impressão digital de alto padrão, o papel impresso de ótima qualidade (couché com alta gramatura um fosco o outro brilhante) e aplicação de resina localizada. Em relação ao conteúdo, as fotos são clean realçando os produtos, os locais são agradáveis, também não utiliza modelo nas fotografias, possui também um catálogo, em anexo, com as referências dos produtos para solicitações dos clientes.

Figura 2 - Catálogos por marcas do Grupo Coteminas



A

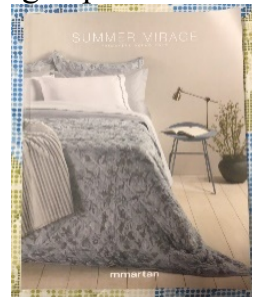

$\mathrm{B}$

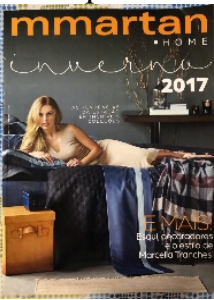

$\mathrm{C}$

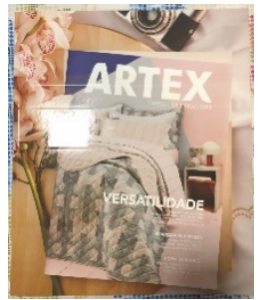

$\mathrm{D}$



$\mathrm{E}$

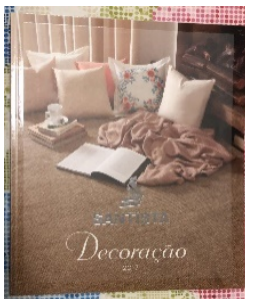

$\mathrm{F}$

Fonte: Autores.

Legenda: (A) Casa Moysés, (B) MMartan, (C) MMartan revista, (D) Artex, (E) Santista (cama, mesa e banho) e (F) Santista (decoração).

\subsubsection{Os espaços de vendas}

As análises dos espaços de venda foram a partir da localização, layout da loja e movimentos dos clientes.

_ Casa Moysés (Figura 3A), as lojas são em locais nobres como shoppings de alto poder aquisitivo, o ambiente é personalizado com a identidade da essência olfativa. Os produtos da Casa Moysés ficam em um ambiente específico da loja MMartan. As lojas são padronizadas, clean com intuito de destacar os produtos. Em relação a quantidade de clientes é confortável, podendo dizer com pouco clientes. 


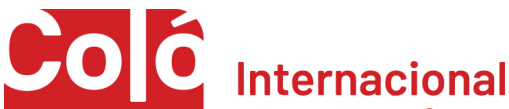 \\ gü de design \\ EDIÇÃO 2020}

_ MMartan (Figura 3B), as lojas são em locais nobres como shoppings de alto poder aquisitivo, o ambiente é personalizado com a identidade da essência olfativa. As lojas são padronizadas, clean com intuito de destacar os produtos. Em relação a quantidade de clientes é confortável, podendo dizer com pouco clientes.

_ Artex (Figura 3C), as lojas são em locais nobres como shoppings, o ambiente é personalizado com essência olfativa. As lojas são padronizadas com intuito de destacar os produtos, são grandes, apresentam alguns espaços com ilhas de produtos. Em relação a quantidade de clientes é confortável, podendo ter movimento ideal de clientes.

_ Santista (Figura 3D), não há lojas próprias, se localiza em magazines, lojas de departamento, supermercados dentre outros. A exposição dos produtos, estão em prateleiras personalizado com intuito de apresentá-los, alguns produtos estão localizados em ilhas. Em relação a quantidade de clientes é alto fluxo de pessoas.

Figura 3 - Espaços de vendas por marcas do Grupo Coteminas



A

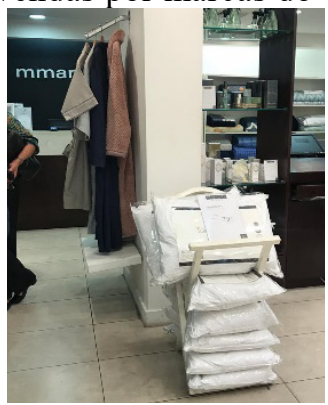

B



$\mathrm{C}$



$\mathrm{D}$

Fonte: Autores.

Legenda: (A) Casa Moysés, (B) MMartan, (C) Artex e (D) Santista.

\section{Conclusão}

A partir do ponto intencional da empresa em relação ao público alvo de cada marca (Casa Moysés, Mmartan, Artex e Santista), podemos concluir que o Grupo Coteminas obtém seus objetivos e tem capacidade de atender conforme o público que deseja atingir.

Portanto os tópicos analisados como produtos, catálogos e espaços (físico e virtual) de vendas, ocorrem investimentos ou a redução de custos para conseguir adquirir o valor adequado a cada marca, que tem como dever atingir o público alvo.

Concluímos que a importância do conjunto gestão do design e do design thinking auxiliam no processo de desenvolvimento o produto, do momento que surge a ideia até a finalização, agregando valor e a criando motivação para a aquisição. 
TEXTILE HOME: design management of Coteminas Group's national brands

\section{Abstract:}

The present study brings an analysis of the four most important brands of the Coteminas Group (Springs Global). The company was chosen because it is one of the largest industries in Brazil and its textile chain is fully verticalized. The analyzed brands were Casa Moysés, Mmartan, Artex and Santista selected because they are part of the Brazilian domestic consumption. The starting point for the survey was an interview with the CEO Mário Sette, who ranks the target audience for each brand. The next step was to visit the stores in the field, analyze the stores' layout, obtain physical and digital catalogs and analyze the products of each brand. With the set of data and images obtained, it was possible to explore the process of design management for each brand and the implementation of design thinking in the products (home textiles and decoration).

Key words: design; management; home textile; Coteminas Group

\section{Referências bibliográficas}

BEST, Kathryn. Design management: managing design strategy, process and implementation. AVA publishing, 2006.

CORRAL, C. B. Product innovations drove strong bath market. Home Textiles Today, v. 26, n. 39, p. 10, 2005.

DAS, S. Performance of home textiles. $1^{\text {a }}$ ed. New Delhi: Woodhead Publishing India PVT, 2010.

ELMUTI, Dean; KATHAWALA, Yunus. An overview of benchmarking process: a tool for continuous improvement and competitive advantage. Benchmarking for Quality

Management \& Technology, v. 4, n. 4, p. 229-243, 1997.

GIL, A. C. Métodos e técnicas de pesquisa social. 6. ed. São Paulo: Atlas, 2008.

GRUPO COTEMINAS AS (Springs Globo AS). Empresa. São Paulo: Coteminas, 2018. Disponível em:

<http://www.coteminas.com.br/scripts11/cgiip.exe/WService=coteminas/cot/vis/home.htm>. Acesso em: 22 jul. 2018.

HARRIS, J. $\mathbf{5 0 0 0}$ years of textiles. $1^{\text {a }}$ ed. reprint. London: The British Museum Press, 2006.

INSTITUTO DE ESTUDOS E MARKETING INDUSTRIAL. Brasil Têxtil, 2015: relatório setorial da indústria têxtil brasileira. São Paulo: IEMI, 2015.

LAKTIM, Mariana Costa. Cama, mesa e banho: desenvolvimento de materiais e processos têxteis, design e moda no Brasil (1976-2017). Banco de tese da USP. Universidade de São Paulo, 2018.

NIXON, Natalie W. (Ed.). Strategic Design Thinking: Innovation in Products, Services, Experiences and Beyond. Fairchild Books, 2016. 


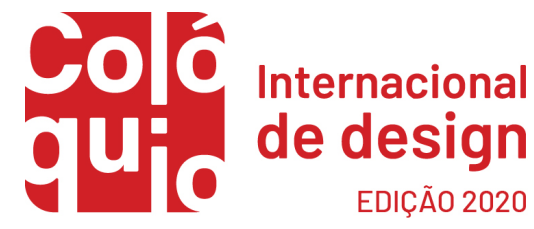

PINTO, D. F.; PINTO, R. C. A.; MOTA, M. D. B. Enxoval de casamento: cultura e mercado na (re) significação de uma tradição. In: CONGRESSO BRASILEIRO DE ECONOMIA DOMÉSTICA, 20.; ENCONTRO LATINO-AMERICANO DE ECONOMIA DOMÉSTICA, 8.; ENCONTRO INTERCONTINENTAL DE ECONOMIA DOMÉSTICA, 1.; 2009, Fortaleza, CE. Família e economia doméstica. Fortaleza: Wave Media, 2009. v. 1, p. 1-12.

SHETTY, Y. K. Aiming high: competitive benchmarking for superior performance. Long Range Planning, v. 26, n. 1, p. 39-44, 1993.

SPENDOLINI, Michael J. The benchmarking process. Compensation \& Benefits Review, v. 24, n. 5, p. 21-29, 1992.

VERGARA, S. C. Começando a definir a metodologia. In: VERGARA, S. C. Projetos e relatórios de pesquisa em administração. 3. ed. São Paulo: Atlas, 2000. p. 46-53.

YILMAZ, N. D.; POWELL, N. B.; DURUR, G. The technology of terry towel production. Journal of Textile and Apparel, Technology and Management, v. 4, n. 4, p. 1-43, 2005.

Disponível em: < https://textiles.ncsu.edu/tatm/wp-

content/uploads/sites/4/2017/11/Yilmaz_full.pdf>. Acesso em: 22 jul. 2018. 